\title{
Nutritional Value and Anthocyanins of Mulberry and Roselle Mixed Fruits Jam
}

\author{
Ruthai Wongchalat ${ }^{1, a}$ and Rassarin Chatthongpisut ${ }^{2, b^{*}}$ \\ ${ }^{1,2}$ School of Food Science and Technology, Department of Agriculture and Environment, \\ Faculty of Science and Technology, Surindra Rajabhat University, Nokmueang, Mueang District, \\ Surin, Thailand \\ aruethaidaung@gmail.com, bjumrassarin@gmail.com*
}

\section{Keywords: Jam, Mulberry, Roselle, Anthocyanins}

\begin{abstract}
Mulberry and roselle are widely consumed in Thailand both as fresh and in processed forms. The objectives of this study were to develop mulberry and roselle mixed fruits jam and to study the nutritional value and anthocyanins content of the finished product having highest sensory score. Formulations of mixed fruits jam based on roselle and mulberry in five different ratios, 70/30, 60/40, 50/50, 40/60 and 30/70 was developed. Sensory analysis was carried out with 10 nontrained panelists using a structured 9-point hedonic scale to evaluate sensory acceptance. The highest score of overall acceptance of mixed fruits jam was analyzed nutritional value, total anthocyanins content, total microorganisms, and yeast and mold. The results showed that no significant difference of sensory scores from all formulations of mixed fruit jam was found $(\mathrm{P}>0.05)$ in all sensory attributes, and the liking scores were in the range of 6-7 which mean slightly to moderately liking. However, mixed fruits jam based on roselle and mulberry in the ratios of 70/30 was the highest score for overall acceptability (6.4). Thus, the nutritional value of this mixed fruits jam product found that moisture content, carbohydrate, protein, fat and total minerals were $24.96 \%, 74.03 \%, 0.34 \%, 0.01 \%$ and $0.66 \%$ respectively. The $\mathrm{pH}$, total soluble solids and total anthocyanins content of this product were $2.98,68{ }^{\circ}$ Brix and $538.84 \mathrm{mg} / 100 \mathrm{~g}$. Microbiological analyses revealed that the mixed fruit jam product showing the highest overall acceptability presented a total number of microorganisms, and yeasts and molds $<10 \mathrm{cfu} / \mathrm{g}$, which is above the expected level of jam community standards of Thailand. Thus, this mixed fruits jam product may have great potential for sales due to high nutritional value and anthocyanins content because anthocyanins were considered to play an important role as dietary antioxidants for the prevention of oxidative damage in living system.
\end{abstract}

\section{Introduction}

Jam is an intermediate moisture food and widely used to accompany a variety of dishes such as pancakes, pudding and bread. Jam is prepared by boiling whole fruit, pieces of fruit, the unconcentrated and/or concentrated fruit pulp or fruit puree, of one or more kinds of fruit with sugar (sucrose), pectin, acid, and other ingredients (preservative, coloring and flavoring material) to a reasonably thick consistency, firm enough to hold the fruit tissues in position [1,2, and 3]. One parameter should be concerned for jam production is total soluble solids (TSS) content. The finished jam or preserve should contain of TSS between $60 \%$ and $65 \%$ or greater and the product should contain fruit $45 \%$ or less than depending on kinds of fruit [4].

Roselle (Hibiscus sabdariffa L.) is a shrub and commonly used to make beverages, jellies and jams because of its red color and unique flavor [5]. The brilliant red pigment of roselle calyces contains anthocyanins, that are soluble flavonoids pigments and the major anthocyanins were identified as delphinidin and cyanidin [6]. Mulberry (Morus alba L.) is an important crop in Thailand for cultivation silk worm (using leaves) in silk production of Thai people for centuries. In the past, mulberry fruits are as by product but they are widely consumed in the form of fresh fruit and the processed forms at the present. Fresh mulberry fruits are very perishable and since they become to be black color, they will be soft quickly and need to eating immediately or store at the 
refrigerator or freezer for a long time. Mulberry fruits are not only for its nutritional qualities and flavor, but also for its traditional use as traditional Chinese medicine, used for dizziness and blurred vision [7]. Mulberry fruits are a rich of anthocyanins and the predominant anthocyanins identified were cyanidin-3-glucoside, cyanidin-7-glucoside, cyanidin-3-galactoside, cyanidin-3-rutinoside, cyanidin-3-rhamnoglucoside and cyanidin-3-rhamnogalactoside [7,8]. Recently, the biological activities of anthocyanins such as antioxidant, anti-inflammatory, anti-cancer activity and chemoprotective properties were investigated [5]. Many studies have shown that anthocyanins may have potential effect in reducing the risk of cardiovascular disease, cancer, stroke, certain epithelial cancers, visual impairments, arthritis, and asthma [6,7]. Therefore, Anthocyanin pigments have been recognized in disease prevention through their effects on oxidative damage [7]. The objectives in the present study were to (1) develop mixed fruits jam from roselle and mulberry and (2) study chemical composition and the nutritional value of the roselle and mulberry mixed fruit jam product having highest sensory score for overall acceptability.

\section{Materials and methods}

Materials. Roselle (Sudan variety) and mulberry (Buriram 60 varity) were bought at a supermarket and local market and were kept at $-20{ }^{\circ} \mathrm{C}$ before use. Pectin and citric acid monohydrate were purchased from Chemipan Corporation Co., Ltd. Bangkok, Thailand. Sucrose and Salts were obtained from Mitphol and Prung Thip, Thailand.

Preparation of mixed fruit jams. Dried roselle calyces were processed at $95{ }^{\circ} \mathrm{C}$ for 10 minutes in water $(5: 95 \mathrm{w} / \mathrm{v})$ to $5 \%$ roselle extract. The formulation of five mixed fruits jam treatments was processed. 5\% roselle extracts and blended mulberry fruits in the five different ratios, 70/30, 60/40, $50 / 50,40 / 60$ and $30 / 70$ ) were heated at $90{ }^{\circ} \mathrm{C}$ for 30 minutes. The low-methoxy pectin $5 \mathrm{~g}$ was mixed with salts $5 \mathrm{~g}$ and $100 \mathrm{~g}$ of sucrose, and this mixed ingredient were added and were vigorously stirred and heated at $90{ }^{\circ} \mathrm{C}$ for 15 mins. Afterward, sucrose $385 \mathrm{~g}$ was added and vigorously stirred for 20 minutes. The mixture was removed from heat and cool to $30{ }^{\circ} \mathrm{C}$ in order to measure TTS ( $\left({ }^{\circ} \mathrm{Brix}\right)$ and $\mathrm{pH}$ and the mixture was adjusted $\mathrm{pH}$ by citric acid reach to $\mathrm{pH} 2.8-3.5$ and returned to heat and boil for 1-2 minutes and hot-filled in $100 \mathrm{ml}$ sterilized glass jars and capped with metallic lids, cooled and refrigerated at $4{ }^{\circ} \mathrm{C}$. Mixed fruits jams were analyzed for sensory quality at weekly interval for four weeks.

Sensory analysis. The five mixed fruit jams form roselle and mulberry treatments were subjected to hedonic testing. Sensory analysis was carried out with 10 non-trained panelists. Each panelist was provided with a questionnaire and was asked to evaluate each sample based on color, odor, taste, textural mouth feel, spreadability and overall acceptability using a nine-point hedonic scale scoring test.

Determination of total soluble solids, $\mathbf{p H}$ and nutritional value of jam. Total soluble solid contents were determined by Abbe refractometer and expressed as degrees Brix ( $\left.{ }^{\circ} \mathrm{Brix}\right)$. The $\mathrm{pH}$ was measured using a digital $\mathrm{pH}$ meter (Satorious, Germany) calibrated with $\mathrm{pH} 4$ and 7 buffers before use. The moisture content, protein, ash, and fat content were quantified according to AOAC [9]. Carbohydrate was determined by difference.

Determination of total anthocyanins content (TA). Mixed fruits jam was extracted anthocyanins using acidified methanol as described by Kopjar et al. [10]. The sample was held at $4{ }^{\circ} \mathrm{C}$ overnight and centrifuged for $10 \mathrm{~min}$ at $4000 \mathrm{rpm}$. The TA content was determined according to the $\mathrm{pH}$ differential method [11]. TA was expressed as cyanidin-3-glucoside (mg/100 $\mathrm{g}$ of $\mathrm{dw}$ of sample). Sample was analyzed in triplicate.

Microbiological Analyses. Microbiological evaluation was done to determine the presence of total microorganisms and yeast and molds ( $\mathrm{cfu} / \mathrm{g}$ ). The pour plate and spread plate techniques were used in this evaluation.

Statistical Analyses. One way analysis of variance (ANOVA), with least significant difference (LSD) test $(\mathrm{p}<0.05)$ was carried out using SPSS. 


\section{Results and discussion}

Sensory score attributes. The one most important characteristic of food is color. The appearance of all the jam formulations had red to reddish purple color depending on the ratio of mulberry. An increase of mulberry fruits will have increased purple color of jam. From red color in the treatment $\mathrm{A}$ which is a rich of roselle $(70 \%)$ and low content of mulberry $(30 \%)$ become to reddish purple color in the treatment $\mathrm{E}$ (mulberry 70\%). The texture of jam treatments with $60 \%$ and $70 \%$ mulberry fruits had high viscosity and decreased spreadability values making the jam difficult to spread. To establish a good quality roselle and mulberry mixed fruit jam, mulberry fruit content at least $50 \%$ would produce a jam of acceptable spreadability.

Table 1 Hedonic sensory scores of roselle and mulberry mixed fruit jams

\begin{tabular}{|c|c|c|c|c|c|c|}
\hline \multirow[b]{2}{*}{ Treatments } & \multicolumn{6}{|c|}{ Parameters } \\
\hline & Color $^{\text {ns }}$ & Odor $^{\mathrm{ns}}$ & Texture $^{\mathrm{ns}}$ & flavor $^{\text {ns }}$ & Spreadability $^{\text {ns }}$ & $\begin{array}{c}\text { Overall } \\
\text { Acceptability }^{\mathrm{ns}}\end{array}$ \\
\hline A & $6.83 \pm 0.14$ & $6.37 \pm 0.20$ & $6.63 \pm 0.18$ & $6.37 \pm 0.23$ & $6.60 \pm 0.21$ & $6.37 \pm 0.20$ \\
\hline B & $6.57 \pm 0.16$ & $6.27 \pm 0.23$ & $6.30 \pm 0.23$ & $6.67 \pm 0.22$ & $6.40 \pm 0.22$ & $6.27 \pm 0.19$ \\
\hline $\mathrm{C}$ & $6.53 \pm 0.16$ & $6.30 \pm 0.21$ & $6.53 \pm 0.21$ & $6.77 \pm 0.22$ & $6.20 \pm 0.21$ & $6.30 \pm 0.18$ \\
\hline $\mathrm{D}$ & $6.40 \pm 0.20$ & $6.20 \pm 0.21$ & $6.17 \pm 0.20$ & $6.33 \pm 0.26$ & $6.10 \pm 0.24$ & $6.20 \pm 0.21$ \\
\hline $\mathrm{E}$ & $6.40 \pm 0.21$ & $6.23 \pm 0.22$ & $6.37 \pm 0.17$ & $6.40 \pm 0.19$ & $6.00 \pm 0.19$ & $6.00 \pm 0.18$ \\
\hline
\end{tabular}

ns Mean values in the same column are not significantly different $(\mathrm{P}>0.05)$.

Abbreviations $\mathrm{A}, \mathrm{B}, \mathrm{C}, \mathrm{D}$, and $\mathrm{E}$ are mixed fruit jam treatments based on the ratios of roselle and mulberry, $\mathrm{A}=70 / 30, \mathrm{~B}=60 / 40, \mathrm{C}=50 / 50, \mathrm{D}=40 / 60$ and $\mathrm{E}=30 / 70$.

The sensory profile of all roselle and mulberry mixed fruit jam formulations was evaluated in terms of color, odor, texture, flavor, spreadability and overall acceptability, average hedonic scores of sensory attributes are reported in Table 1. There was no significant difference $(\mathrm{P}>0.05)$ in all sensory attributes of all mixed fruit jam treatments. However, it was observed that an increase of the ratio of mulberry resulted in decreasing trend of sensory attributes for color, spreadability and overall acceptability. These results indicate that color and spreadability may be an important characteristic for good quality jam and influence to consumer acceptance and purchase decision. Hedonic scores of all mixed fruit jam treatments showed that the liking scores were in the range of 6-7 which mean slightly to moderately liking. However, mixed fruits jam based on roselle and mulberry in the ratio of 70/30 (treatment A)(Fig.1) was the highest score for overall acceptability ( 6.4). Thus, treatment A was selected to determine chemical composition and nutritional value.

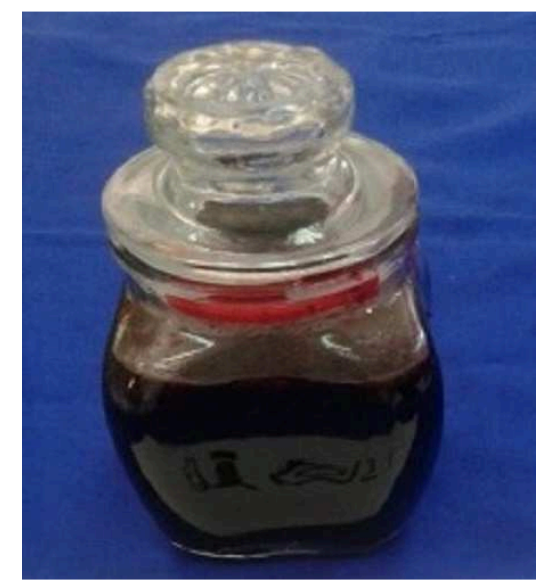

Fig. 1 Roselle and mulberry mixed fruit jam (treatment A, ratio of roselle and mulberry is 70/30)

Chemical composition and nutritional value of jam. The chemical composition and nutritional value of treatment $A$ are shown in Table 2. Traditionally, the soluble solids content for the jam products shall be $40-65^{\circ}$ Brix or less according to CODEX STAN 296-2009 [4]. Whereas, $68^{\circ}$ Brix was observed in this study may be cause by the content of mulberry, the concentration effect during 
processing, and the addition of pectin. Furthermore, the experiment was designed the lowest content of roselle and mulberry was $30 \%$. It is interesting idea in producing a brilliant red coloring for making jam, jellies and other products from roselle because roselle calyces contain ascorbic acid and pectin [6]. Interestingly, TA level in mixed roselle and mulberry mixed fruit jam in this study was found to be $\sim 135$ fold higher than those reported by Kamiloglu et al. [8]. They found lower levels of TA levels in mulberry jam $(4.0 \mathrm{mg} / 100 \mathrm{~g} \mathrm{dw})$ compared to the value obtained in this study. However, mulberry products had low TA when compared to the fresh mulberry fruits $(1221 \mathrm{mg} /$ $100 \mathrm{~g} \mathrm{dw}$ ) [8, 12]. Surprisingly, a little or no information about TA content in roselle calyces and roselle extract was found. Most of papers only focus on identification of individual anthocyanins in different roselle varities and product development. The major anthocyanins in roselle calyces were identified as delphinidin and cyanidin [6].

Table $2 \mathrm{pH}$, total soluble solids, total anthocyanin content, moisture content, and nutritional value of roselle and mulberry mixed fruit jam (treatment A).

\begin{tabular}{lc}
\hline \multicolumn{1}{c}{ Parameters } & $\begin{array}{c}\text { Roselle and mulberry mixed fruit jam } \\
\text { (Treatment A) }\end{array}$ \\
\hline $\mathrm{pH}$ & 2.98 \\
Total soluble solids $\left({ }^{\mathrm{o}} \mathrm{Brix}\right)$ & 68 \\
Total anthocyanin content $(\mathrm{mg} / 100 \mathrm{~g})$ & 538.84 \\
Moisture content $(\%)$ & 24.96 \\
Protein $(\%)$ & 0.34 \\
Fat $(\%)$ & 0.01 \\
Ash $(\%)$ & 0.66 \\
Carbohydrate $(\%)$ & 74.03 \\
\hline
\end{tabular}

While identified anthocyanins in mulberry fruits were cyanidin-3-glucoside, cyanidin-7glucoside, cyanidin-3-galactoside, cyanidin-3-rutinoside, cyanidin-3-rhamnoglucoside and cyanidin-3-rhamnogalactoside. [7, 8]. Besides anthocyanins, phenolic acids such as chlorogenic, syringic, neochlorogenic, caffeic and gallic acid were determined in the study by Kamiloglu (2013), and gallic acid was found to be the highest in mulberry jam $(p<0.05)$.

Results regarding to nutritional value in the terms of moisture content, protein, fat, ash and carbohydrate of roselle and mulberry mixed fruit jam showed that mixed fruit jam in this study had high calories. The product may not prefer for health conscious consumers although it has a rich anthocyanins, natural antioxidant. The microbial results indicated that mixed fruit jam in this study had less than of $10 \mathrm{cfu} / \mathrm{g}$ of total microorganism, and yeasts and molds which are similar to the study by Broomes et al. (2010). Therefore, this roselle and mulberry mixed fruit jam is in a standard for fruit and herb jam because the microbial values are above the expected level of jam community standards of Thailand.

\section{Conclusions}

The judicious mixing of roselle and mulberry in the ratio of 70/30 showed the highest sensory score for overall acceptability. This formulation shows a rich in anthocyanins content and high nutritional value. Regular consumption of anthocyanin-rich foods may play an important role for the prevention of oxidative damage in human living system and decrease the risk of cardiovascular disease, diabetes, arthritis and cancer [13]. However, development of a low-calories roselle and mulberry mixed fruit jam may be good idea for the next study because market for the health conscious consumers and diabetic persons increase quickly at the present.

\section{Acknowledgements}

This study was totally supported by the School of Food Science and Technology, Department of Agriculture and Environment, Faculty of Science and Technology, Surindra Rajabhat University, Thailand. 


\section{References}

[1] S. Basu, U.S. Shivhare, T.V. Singh, V.S. Beniwal, Rheological, texture and spectral characteristics of sorbitol substituted mango jam, Journal of Food Engineering. 105 (2011) 503-512.

[2] G. Lal, G. S. Siddappaa, G. L. Tandon, Preservation of fruit and vegetables, ICAR Publication, New Delhi, 1998.

[3] R. A. Baker, N. Berry, Y. H. Hui, D. M. Barrett, Food preserves and jams, third ed., in: D. M. Barrete, L. Somogyi, H. S. Ramaswamy Jones (Eds.), CRC Press, Boca Raton, 2005, pp. 113-125.

[4] Information on http://www.fao.org/fao-who-codexalimentarius/standards/list-standards/en/

[5] P.-J. Tsai, J. McIntoshb, P. Pearceb, B. Camdenb, B. R. Jordanc, Anthocyanin and antioxidant capacity in Roselle (Hibiscus sabdariffa L.) extract, Food Research International. 35 (2002) 351356.

[6] J. Broomes, N. Badrie, Effect of low-methoxy pectin on physicochemical and sensory properties of reduced-calories sorrel/roselle (Hibiscus sabdariffa L.) jams, The Open Food Science Journal. 4 (2010) 48-55.

[7] Q. Du, J. Zheng, Y. Xu, Composition of anthocyanins in mulberry and their antioxidant activity, Journal of Food Composition and Analysis. 21 (2008) 390-395.

[8] S. Kamiloglu, O. Serali, N. Unal, E. Capanoglu, Antioxidant activity and polyphenol composition of black mulberry (Morus nigra L.) products, Journal of Berry Research. 3 (2013) 4151.

[9] AOAC. Official methods of analysis of AOAC international. Seventeenth ed. Gaithersburg, Md: AOAC International (2000)

[10] M. Kopjar, V. Poližota, N. N. Tiban, D. Šubarić, J. Babić, Đ. Ačkar et al., Strawberry jams: Influence of different pectins on color and textural properties, Czech J0urnal of Food Science. 27 (2013) 20-28.

[11] M. M. Giusti, R. E. Wrolstad, Characterization and measurement of anthocyanins by UVvisible spectroscopy, in: Current Protocols in Food Analytical Chemistry, John Wiley \& Sons, Inc., New York, 2001, pp. F1.2.1-F1.2.13.

[12] M. Ozgen, S. Serce, C. Kaya, Phytochemicals and antioxidant properties of anthocyanin-rich Morus nigra and Morus rubra fruits, Scientia Horticulturae. 119 (2009) 275-279.

[13] L-S. Wang, G. D. Stoner, Anthocyanins and their role in cancer prevention, Cancer Letter. 269 (2008) 281-290. 